\title{
LIBERDADE E IGUALDADE NO PENSAMENTO UTÓPICO DE ETIENNE CABET
}

\author{
Rodrigo Wünsch Manika \\ Orientação: Ana Paula Vosne Martins
}

PALAVRAS-CHAVE: Utopia; Liberdade; Igualdade.

O objetivo deste trabalho é analisar a proposta socialista criada por Etienne Cabet durante a primeira metade do século XIX e publicada no livro Travels in Icaria ${ }^{1}$. A proposta do socialismo utópico demonstrava uma realidade incongruente ${ }^{2}$, o autor observava ao seu redor e por meio da elaboração da crítica selecionava o que considerava ser o potencial dessa sociedade. A utopia olha para o presente e busca o novo, analisando as possibilidades da época e, em dissonância, apresenta algo diferente da realidade ${ }^{3}$, enquanto a visão ideológica do autor encontrava-se orgânica e harmoniosamente integrada dentro de uma visão de mundo da época.

Grande parte do desmerecimento do pensamento utópico foi fruto da crítica de Karl Marx. Ele reconhecia o valor dos socialistas utópicos no ataque aos princípios da sociedade burguesa, mas questionava a recusa à ação revolucionária. ${ }^{4}$

Etienne Cabet nasceu em 1788, filho de um mestre torneiro mecânico na cidade de Dijon. Exerceu o direito em Paris após o governo dos 100 dias de Napoleão Bonaparte, tornando-se um republicano radical no mesmo período. Agregou-se à Carbonaria de La Fayette, porém afatou-se por considerar as sociedades secretas

\footnotetext{
${ }^{1}$ CABET, Etienne. Travels In Icaria. New York ; Syracuse University Press, 2003.

${ }^{2}$ MANNHEIM, Karl Ideologia e Utopia. Rio de Janeiro: Jorge Zahar Ed., 1982, p. 216.

${ }^{3}$ SZACKI, Jerzy. As Utopias ou A Felicidade Imaginada. Rio de Janeiro: Paz e Terra, 1972, p. 12.

${ }^{4}$ ROCHA, Suzana Munhoz da. A terra permitida: um estudo sobre o socialismo utópico. Tese de doutorado. Universidade Federal do Rio de Janeiro, Departamento de Filosofia, Rio de Janeiro, p. 36.
} 
ineficientes. Após o exílio do monarca Carlos X no ano de 1830 e a instauração de uma monarquia constitucional com Luis Filipe I, Etienne Cabet foi convidado por Dupont de l'Eure, ministro da justiça, a exercer o cargo de Procurador Geral do Tribunal de Recursos da cidade de Bastia. Tendo sido destituído de seu cargo por discordância com o governo Francês no ano de 1831, Cabet continuou com a sua participação política ao eleger-se deputado para a Côte-d`Or - departamento administrativo criado durante a Revolução Francesa formado pela antiga província de Borgonha - em julho do mesmo ano.

Logo após Cabet lançou seu próprio jornal, o Le Populaire no ano de 1833 e por causa de suas idéias foi acusado de crime de imprensa devido à divulgação do ideário jacobino, sendo forçado ao exílio na Inglaterra no ano de 1834. Seu tempo de exílio em Londres serviu para o amadurecimento político e econômico de suas idéias e também escreveu o livro Histoire Populaire de La Revolutión Française de 1789 a 1830. Durante este período foi um republicano radical e um jacobinista exaltado, profundo admirador do filósofo Jean-Jacques Rousseau, de Robespierre e dos demais membros do Período do Diretório. No ano de 1839 ele publicou Voyages et aventures de Lord William Carisdall en Icarie, sob pseudônimo de Francis Adams com tradução para o francês de Th. Dufruit, apesar desse livro não ter sido lançado na Inglaterra antes da França. Porém no ano de 1840 Cabet o livro passou a ser publicado com o título mais conciso Voyage en Icarie e passou a ser assinado pelo próprio. Seu livro rapidamente foi traduzido para diversas línguas, entre elas o inglês, alemão, e espanhol e adquiriu popularidade entre os trabalhadores.

Para qualquer francês a Inglaterra era um país muito atraente nessa época devido a Revolução Industrial e às novas formas de trabalho ainda desconhecidas em diversas regiões do continente europeu. Lá Cabet teve contato com a causa dos trabalhadores. Observou a riqueza que a industrialização produziu na Inglaterra, ao mesmo tempo em que verificou os custos humanos desse 
desenvolvimento. Cabet teve contato com as ideias do socialista inglês Robert Owen, que defendia a necessidade do governo "contrabalancear os males da industrialização através da interferência de diretrizes legislativas". ${ }^{5}$ Enquanto na França sentiu a opressão política do retorno monarquista, na Inglaterra teve contato com a opressão econômica.

Buscando entender essa situação vivida por Etienne Cabet, procurei identificar de que forma alguns conceitos herdados pela Revolução Francesa são apresentados e resignificados em sua utopia. Os dois principais temas abordados foram os conceitos de Liberdade e Igualdade, possivelmente as duas maiores heranças dessa revolução e talvez as mais contraditórias concepções da mesma. O conceito de liberdade $^{6}$, que em seu sentido mais amplo procurava permitir ao homem expor a sua verdadeira individualidade, é limitado pela idéia de igualdade, pelo direito que o outro possui de também ser livre. Esta, em sua concepção mais ampla, encontrava barreiras na liberdade dos outros indivíduos. A liberdade dos homens era limitada pela igualdade dos demais e a igualdade dependia da extensão da liberdade de todos.

Neste trabalho levei em consideração que para o ideal socialista o bem estar coletivo estava acima de qualquer outro. ${ }^{7}$ A liberdade e a igualdade teriam que se submeter à essa idéia de comunidade. Se a liberdade e a igualdade já apresentavam suas limitações quando em conjunto, a busca pelo bem estar social deveria servir como uma limitação ainda maior a esses conceitos. O trabalho verificou as restrições impostas à liberdade e a igualdade para a existência e permanência da sociedade. Para essa pesquisa foram escolhidos três aspectos da sociedade utópica para pensarmos os

${ }^{5}$ HOBSBAWN, Eric. Revolução Industrial inglesa ao Imperialismo. Rio de Janeiro: Editora Forense, p. 62.

${ }^{6}$ OZOUF, Mona. Liberdade. In: Dicionário Crítico da Revolução Francesa. Ed. Nova Fronteira; Rio de Janeiro, 1989, p. 740.

7 RAYNAUD, Philippe. Democracia. In: Dicionário Crítico da Revolução Francesa. Rio de Janeiro: Nova Fronteira, 1989, p. 676. 
conceitos de liberdade e igualdade conforme estão presentes no livro de Etienne Cabet: A educação, que é o fundamento do desenvolvimento racional até a fase adulta do cidadão; o trabalho, ou seja, toda a atividade produtiva organizada pelo Estado; a religião, que junto com a educação tem por fundamento o desenvolvimento moral do indivíduo dentro da Republica de Icaria.

O conceito de utopia foi discutido a partir das obras de Karl Mannheim $^{8}$, Jean-Christian Petitfils ${ }^{9}$ e Jerzy Szacki ${ }^{10}$. Para a melhor compreensão do contexto histórico da formulação do pensamento utópico recorri aos trabalhos de Eric Hobsbawn ${ }^{11}$, à tese de doutorado de Suzana Maria Munhoz da Rocha Guimarães ${ }^{12}$ e para pensar sobre o lugar da religiosidade naquele contexto recorri ao livro de Ignasi Terradas Saborit $^{13}$, e também às considerações Mona Ozouf ${ }^{14}$.

No primeiro capítulo verifiquei como a educação de Icaria articula os conceitos de Liberdade e Igualdade. O sistema educacional em Icaria possuía caráter universal e estava voltado para o mundo do trabalho. Acreditando na possibilidade de aperfeiçoar infinitamente a natureza humana, a educação deveria servir ao mesmo fim, propiciando as condições morais e intelectuais para a emancipação do homem contra a tirania.

A liberdade estava presente também na escolha da profissão com a qual o aluno acreditava melhor poder servir à nação. Essa escolha estava limitada pela felicidade geral da comunidade, pois o jovem deveria levar em consideração a melhor forma de servi-la. A felicidade coletiva deveria pesar mais nesta escolha do que a

\footnotetext{
${ }^{8}$ MANHEIM, op. cit. .

9 PETITFILS, Jean-Christian. Os Socialismos Utópicos. São Paulo: Círculo do Livro, 1977.

${ }^{10}$ SZACKI, op. cit. .

11 HOBSBAWM, Eric. A Era das Revoluções: 1789-1848. São Paulo: Paz e Terra, 1993.

12 ROCHA, op. cit.

13 SABAROTI, Ignasi Terradas, Religiosidade na Revolução Francesa. Rio de Janeiro: Imago Ed. 1989.

${ }^{14}$ OZOUF, Mona. Religião Revolucionária. In: Dicionário...
} 
felicidade individual. O conceito de liberdade era construído como um mecanismo para a emancipação dos cidadãos da república e realizado por meio do trabalho, e não como emancipação individual. A propaganda da igualdade segue como a potência da liberdade. Enquanto a liberdade visava melhor servir o coletivo, a igualdade encontrava-se no direito à educação.

No segundo capítulo verifiquei a importância do trabalho para Etienne Cabet. A industrialização é apresentada como mecanismo de opressão social para a classe trabalhadora desde sua implantação na Inglaterra. Propus-me a verificar as características do trabalho para os propósitos da Liberdade e da Igualdade dos trabalhadores de Icaria. Profundamente influenciado pela corrente materialista francesa, que defendia que o homem era resultado das circunstâncias, portanto, a criação de uma nova humanidade era dependente da criação de uma nova circunstância que permitira ao homem a exposição de sua verdadeira humanidade $^{15}$, o trabalho deveria refletir esse pensamento.

O trabalho deveria ser reestruturado para permitir a emancipação do homem e consequentemente da sociedade a fim de garantir os bens necessários para todos os cidadãos da República. Procurar meios para que o trabalho fosse executado da maneira menos cansativa e menos humilhante para os cidadãos era considerado por Cabet uma das bases funcionais do governo. Esta ideia garantiria o surgimento de um homem mais feliz com a sua condição de trabalhador e consequentemente ele seria mais produtivo. As máquinas e as linhas de montagem serviriam para auxiliar o Estado na aquisição desse fim. O governo era o único organizador do trabalho e o único proprietário das matérias-primas, dos meios de produção, do produto do trabalho e do próprio trabalho. A alienação do trabalho deveria ser alimentada, segundo o autor, para facilitar e aumentar a produção das fábricas, em contrapartida os trabalhadores teriam jornadas de trabalho reduzidas. A produção coordenada pelo Estado estabeleceria planos de metas da produção, primeiramente

${ }^{15}$ ROCHA, op. cit., p. 67. 
procurando suprir o necessário e depois os bens considerados supérfluos.

A padronização do trabalho para o bem comum retirava do homem um dos aspectos mais individualizantes, senão mais humanizantes do ser, a sua criatividade e o seu talento. Nenhum homem dentro de um ramo profissional efetuava uma atividade diferenciada dos demais. $\mathrm{O}$ discurso do autor afirmava a importância de todos os trabalhadores para o bem da sociedade e que todos seriam reverenciados pelo serviço prestado e não pela complexidade de sua atividade, que estaria condicionada às capacidades recebidas do indivíduo pela natureza. ${ }^{16}$ Apesar desse discurso afirmativo, Cabet não tratava todas as profissões de mesma forma, contemplando algumas profissões como mais essenciais para a República do que outras, mantendo, dessa forma, o ideal meritocrático burguês desenvolvido durante a Revolução Francesa. A igualdade camuflada da República Icariana permitiria o desenvolvimento de uma desigualdade meritocrática. ${ }^{17}$

Ao submeter a liberdade a um mal formulado conceito de igualdade, Cabet permitia o desenvolvimento de uma meritocracia fundamentada no status do trabalho. Cabet utilizava as máquinas e o mesmo princípio da organização fabril da produção visando a grandeza da sociedade Icariana e para a idealização de uma sociedade mais justa, mas não conseguia se libertar das hierarquias da sociedade burguesa, cujas profissões mais valorizadas são aquelas de origem intelectual, tais como juristas e médicos.

No terceiro capítulo analisei o papel da religião em Icaria. Petitfils ${ }^{18}$ demonstrou como a partir de 1840 a utopia deixou de fundar uma nova religião para criar uma nova humanidade e aliou-se ao cristianismo para esse fim. A religião sempre foi vista como uma das principais instituições para a educação moral, consequentemente é um interessante objeto de estudo para a construção das ideias

\footnotetext{
${ }^{16}$ CABET, op. cit., p. 83.

${ }^{17}$ OZOUF, Mona. Liberdade. In: Dicionário..., p. 744.

${ }^{18}$ PETITFILS, op. cit., p. 119.
} 
propostas. Verificou-se em Icaria que o Estado, através o discurso da razão e do bem comum, intervém diretamente na religiosidade da população. Por um lado a legislação promulgava a liberdade religiosa e o Estado fornecia o espaço do culto e garantia a presença de um clérigo para a realização do mesmo. Por outro lado, o Estado fundava uma nova religião deísta de caráter nacionalista, baseada nos preceitos morais caros ao autor, assim como um culto robespierrista que procurava desviar o sentimento de sagrado para a pátria. ${ }^{19}$

Influenciado por Robespierre ${ }^{20}$, Cabet afirmava a existência de um Ser Supremo, promulgava a virtude de servir ao Estado e a vontade da maioria, valorizava a racionalidade humana, ao ponto de não ser permitido às pessoas menores de dezessete anos participarem dos debates religiosos por conta de sua imaturidade intelectual. Obrigava as religiões a se submeterem à autoridade do Estado, porém proibia os poderes espirituais de participarem nos assuntos seculares $^{21}$.

Embora a idéia religiosa do autor seja exposta com cautela e brevidade transparece novamente a desigualdade meritocrática através da busca, na religião, de estabelecer o melhor pai de família, o melhor marido e cidadão. O melhor, sendo adjetivo comparativo, implica na existência de outros conceitos negativos que permitem critérios de desigualdade. A igualdade estaria limitada pela natureza humana, que distribuía capacidades diferenciadas, um conceito aceitável para o autor, porém as instituições religiosas não recebiam o tratamento igualitário que o discurso de liberdade promulgava. O intervencionismo estatal nomeava os clérigos de todas as religiões e mediava os debates religiosos, não se mantendo neutro na questão religiosa. Utilizando-se do discurso de combate ao fanatismo, Cabet previa o controle estatal sobre os cultos por meio de rigorosa fiscalização.

${ }^{19}$ OZOUF, Mona. Religião Revolucionária. In: Dicionário..., p. 605.

${ }^{20}$ SABAROTI, op. cit., p. 219.

${ }^{21}$ CABET, op. cit., p. 139. 
O bem estar da nação e do coletivo reduz a liberdade do indivíduo no direito de melhor servir a nação através da subserviência à vontade de todos, representada pela legislação estatal. Desta forma, a liberdade é um conceito que está diretamente submetido ao bem estar da sociedade icariana e através da restrição das liberdades individuais Cabet fundamentou o conceito de igualdade. A lei limitava as liberdades individuais visando a garantia da igualdade. A igualdade por sua vez seria institucionalizada pelo Estado como a garantia de todos em celebrar contratos, a igualdade individual perante as leis e a igualdade de propriedade. Porém, a sociedade icariana perpetuava desigualdades relacionadas às qualidades individuais e ao reconhecimento dos méritos de seus cidadãos através dos serviços prestados para a República e para sua família não conseguindo manter a proposta igualitária que o autor defende ao longo de sua obra. 